\title{
AVALIAÇÃO ECOTOXICOLÓGICA DA ÁGUA RESIDUÁRIA DO CAFÉ POR MEIO DE BIOENSAIOS COM DANIO RERIO
}

\author{
SOUZA, E. D. V.; HENRIQUES, J. A. ${ }^{1 *}$; JUNIOR, B. S. G. ${ }^{2}$ \& VIEIRA, A. F. S. ${ }^{3}$ \\ 1. Instituto Federal do Espírito Santo (IFES), Coordenadoria do Curso de Engenharia Ambiental, \\ Ibatiba/ES. \\ 2. Instituto Federal do Espírito Santo (IFES), Coordenadoria de Meio Ambiente, Ibatiba/ES.
} 3. Instituto Federal do Espírito Santo (IFES), Ibatiba/ES.

*Autor correspondente: juscelino.henriques@ifes.edu.br

\begin{abstract}
Souza, E. D. V., Henriques, J. A., Junior, B. S. G. \& Vieira, A. F. S. (2020). Ecotoxicological Evaluation of Coffee Residuary Water by Bioensai with Dario rerio. Braz. J. Aquat. Sci. Technol. 24(2). eISSN 1983-9057. DOI: 16267/bjast.v24n2. Ecotoxicological tests with bioindicator organisms provide quick answers on the toxicological potential of certain effluents. Aquatic organisms such as fish have been widely studied by researchers due to their efficiency in ecotoxicological monitoring, since some species undergo behavioral, physiological and morphological changes detected in a short period of time. Thus, the objective of this study was to evaluate the ecotoxicity of coffee wastewater (CW) through standardized bioassays with Danio rerio species, a bioindicator fish known as "paulistinha". The aforementioned test organism was exposed to different concentrations of CW samples diluted in water, without feed and without renewal of the test solution, in order to evaluate the lethal concentration for a period of 48 hours $\left(\mathrm{LC}_{50} 48 \mathrm{~h}\right)$. The test organisms were exposed to effluent samples equivalent to $(1,67 \%, 3,33 \%$ and $5 \% \mathrm{CW})$. At the end of each test, the lethality caused by each concentration was observed. The following mortality percentages were recorded: $84 \%, 60 \%$ and $20 \%$ for the $5 \%, 3,33 \%$ and $1,67 \%$ CWconcentrations, respectively. According to the results obtained and considering the standard norm used, it can be affirmed that the higher the CW concentration, the higher the $\mathrm{LC}_{50} 48 \mathrm{~h}$. Therefore, it is essential to study the pollutant characteristics of the $\mathrm{CW}$ to choose an appropriate treatment, so it is necessary to encourage research and development of new technologies in order to remove the contaminating compounds and minimize the environmental impact of this effluent.
\end{abstract}

Key Words: Ecotoxicity, Bioassays, Environmental monitoring, Water pollution.

\section{INTRODUÇÃO}

Aqualidade dabebidaoriunda dos grãos brasileiros é um fator relevante para o sucesso do produto, além disso, a avaliação da qualidade do café é feita por vários parâmetros que podem prejudicar a qualidade e variam do cultivo até a industrialização (Silva et al., 2015).

O processamento dos frutos do cafeeiro pode ser realizado de duas formas : por via seca "natural", por via úmida "por meio de equipamentos adequados" (Campos et al., 2010). Quando realizado por via úmida, os grãos submetidos à pressão são lançados em um cilindro com diversos furos onde a casca é retirada e separada do fruto, este procedimento é realizado por equipamentos comumente conhecidos como despolpadores de café. Bruno e Oliveira (2008) afirmam que o despolpamento via úmida tem se tornado uma técnica crescente no Brasil devido aos ganhos na qualidade da bebida e valor elevado no mercado.

Paraque os grãos sejam separados comeficiência, os despolpadores utilizam grandes quantidades de água, produzindo um efluente com elevado potencial poluidor, denominado água residuária do café (ARC) (Pin, 2018). Este efluente com alto teor orgânico e inorgânico pode causar mudanças significativas no ambiente, uma vez que interfere na cadeia alimentar, oferece riscos à saúde humana e contamina os cursos d'água provocando alterações em sua qualidade (Campos et al., 2010).

Uma forma segura para avaliar a toxicidade de um efluente é através da utilização de bioensaios ecotoxicológicos, cujo objetivo é identificar os efeitos da ação conjunta de substâncias naturais ou artificiais sobre determinada espécie, sendo ferramentas importantes na avaliação toxicológica (Furley et al., 2018). Estes testes são realizados com organismos denominados bioindicadores ou indicadores biológicos, os quais são classificados como uma espécie ou grupo de espécies capaz de apontar o impacto ambiental produzido por agentes toxicológicos, manifestados através de características como: mudança de comportamento, alterações morfológicas ou adoecimento dos organismos.

Espécies bioindicadoras são abundantes na natureza, compreendendo plantas, animais, fungos, bactérias e etc. Entre estes organismos, os peixes são os mais convenientes para o monitoramento da poluição aquática devido ao seu papel na nutrição de muitas espécies além de ser fonte de renda para muitas populações (Bueno et al., 2017). De acordo com Mello (2017), peixes da espécie Danio rerio são eficientes no monitoramento ecotoxicológico, pois são amplamente utilizados para estudos científicos desde a década de 1930. Esta espécie conhecida 
popularmente como "paulistinha", tem origem asiática, pertence à família dos ciprinídeos e vive em regiões de clima tropical habitando córregos lentos de água doce (Thomé et al., 2016). Apresenta dimorfismo sexual, e em geral exibe coloração prateada com cinco listras horizontais de coloração azul (Silva et al., 2011).

Diante do exposto, objetivou-se avaliar o potencial poluidor da ARC através de bioensaios ecotoxicológicos utilizando o organismo-teste Danio rerio, devido sua ampla distribuição geográfica e hábito alimentar omnívoro, torna essa espécie uma ótima bioindicadora da avaliação da qualidade da água.

\section{Água residuária do café (ARC)}

Um dos principais transtornos do despolpamento do café quando realizado via úmida é o grande volume de água utilizada associada à produção de alta carga poluidora (Oliveira et al., 2010). Segundo Matos \& Lo Mônaco (2003) apud Bruno \& Oliveira (2008), são produzidos em média cerca de 4 litros de água residuária para cada litro de café lavado, descascado e despolpado (Figura 1).

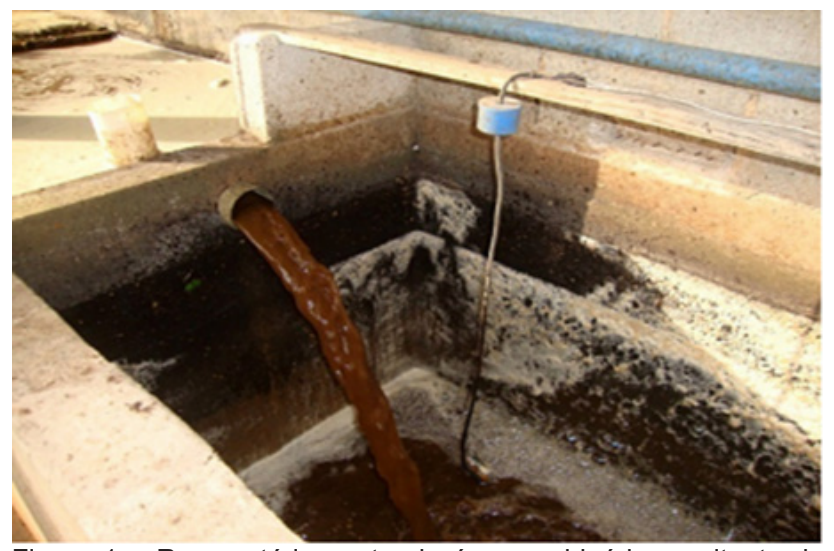

Figura 1 - Reservatório contendo água residuária resultante do processo de despolpamento do café por via úmida (Fonte: Prezotti et al., 2012).

De acordo com a resolução CONAMA $n^{\circ} 430$ de 13/05/2011 (Brasil, 2011) que dispõesobreas condiçõese padrões para o lançamento de efluentes, a ARC pode ser considerada tóxica e extremamente prejudicial para meio ambiente, sendo necessário seu tratamento prévio e adequado antes de ser lançada nos mananciais.

Grande parte da contaminação química de ambientes aquáticos pode ser atribuída aos compostos fenólicos oriundos de águas residuárias (Zanin, 2014). Além de apresentar alta toxicidade, estes compostos são rapidamente absorvidos pelo organismo humano se acumulando em órgãos como o fígado e o pulmão (Bonini et al., 2015). Tais substâncias oferecem riscos à saúde dos seres vivos, podem inibir os processos biológicos, estimular células cancerígenas e atuar como desreguladores endócrinos nos organismos
(Bruno \& Oliveira, 2008). Os compostos fenólicos, encontrados no solo e na água, dificilmente são degradados ou reciclados na natureza, dessa forma podem permanecer por longos períodos no ambiente, causando danos ambientais preocupantes. Devido a seu alto potencial poluidor, são apontados como um dos principais poluentes tóxicos residuais descartados de forma incorreta nos mananciais (Zanin, 2014).

Segundo Campos (2010) a quantidade considerável de compostos fenólicos encontrados na ARC ultrapassa o limite permitido para seu lançamento nos mananciais, descrito pela resolução CONAMA n430 de 13/05/2011 (Brasil, 2011). Importante salientar que os impactos provocados pela ARC não se restringem somente ambientes aquáticos, uma vez que Silva et al., (2011) observou alterações adversas nas propriedades químicas de solos expostos à ARC, o que poderia comprometer sua fertilidade e dificultar o desenvolvimento de vegetais.

\section{Bioensaios ecotoxicológicos com Danio rerio}

Os bioensaios são testes padronizados realizados em laboratório que visam compreender como centenas de substâncias químicas presentes em um efluente afetam a sobrevivência dos seres vivos, investigando seus efeitos adversos sobre determinada espécie. Nos testes supracitados destaca-se o uso de organismos-teste, tais como algas, peixes, invertebrados entre outros, de modo que estes organismos apresentem os impactos provocados pela exposição aos agentes tóxicos (Higashi, 2016).

Para Higashi (2016), o ramo da ecotoxicologia tem sido bastante difundido nos últimos anos, seja por instituições de pesquisa ou por exigência de órgãos responsáveis pelo monitoramento ambiental, constituindo uma ferramenta fundamental para determinar como os agentes tóxicos prejudicam o ambiente e as cadeias alimentares (Alvaro et al., 2010; Costa et al., 2015). Dentre os diferentes tipos de biomonitoramento, o ecotoxicológico revela os agentes tóxicos agressivos ao ambiente e aos seres vivos que o compõe. Brandolt et al., (2010) comprovou a eficácia dos bioensaios com organismos vivos (Daphina magna), demonstrando a importância destes testes no monitoramento ecotoxicológico.

Acerca do organismo-teste, o espécime Danio rerio foi escolhido por ser um excelente bioindicador padronizado internacionalmente para testes de toxicidade, reconhecido pela norma ABNT NBR 15088 (2016). Após a seleção do organismo como bioindicador é preciso considerar os efeitos causados pela solução-teste nos mesmos (Higashi, 2016). O Danio rerio apresenta grande sensibilidade a compostos químicos, absorvendo e acumulando nos tecidos substâncias nocivas presentes no efluente, além de 
promover respostas rápidas e de fácil interpretação durante um curto período de exposição. Várias características favorecem o uso desta espécie no monitoramento ecotoxicológico, entre elas: grande adaptabilidade, facilidade no cultivo e manutenção, facilidade de reprodução em laboratório, entre outros (Silva, 2015).

Por ser um peixe bastante conhecido entre os aquaristas, pode ser facilmente encontrado no comércio de peixes ornamentais por um baixo custo (Silva, 2010). Há diversos estudos relacionados com está espécie, como avaliação ecotoxicológica do efluente hospitalar realizado por Ottonelli (2017). Estes estudos demostram que há uma forte tendência para o uso de peixes no monitoramento ecotoxicológico, seja pela série de facilidades já mencionadas ou por promover respostas confiáveis em tempo hábil frente à exposição aos agentes agressores. A figura 2 apresenta o organismo-teste da espécie Danio rerio.

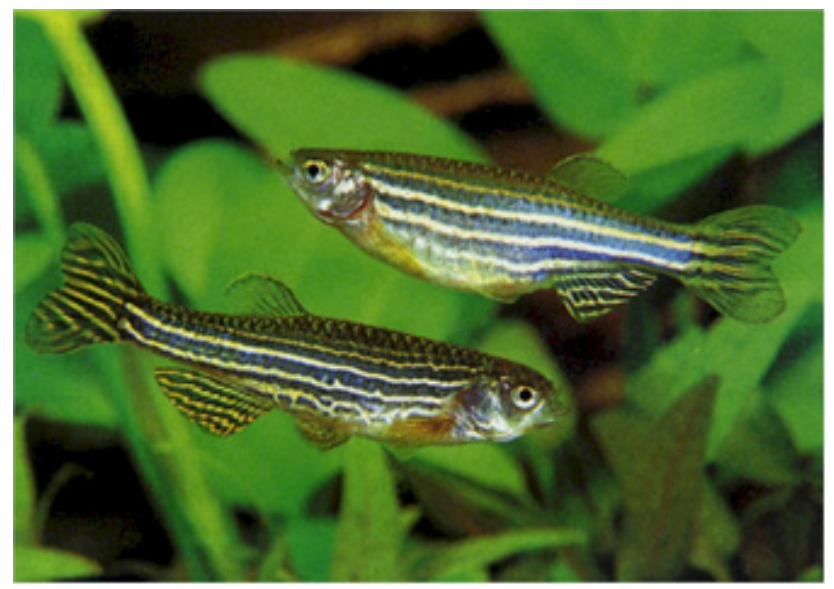

Figura 2 - Espécimes de peixe paulistinha (Danio rerio). A fêmea (acima) é ligeiramente maior em virtude do desenvolvimento dos ovos na região do abdome, o macho (abaixo) apresenta cores fortes e seu o corpo é retilíneo e alongado (Fonte: Aquariaitalia, 2015).

\section{MATERIAIS E MÉTODOS}

Este estudo foi realizado em duas etapas: primeiro, a caracterização do efluente com os equipamentos e métodos (Tabela 1) e, segundo, os bioensaios com os organismos testes.

O organismo-teste Danio rerio foi exposto a diferentes concentrações da amostra de ARC diluídas em água a fim de estimar a Concentração Letal que causa mortalidade em $50 \%$ dos organismos no período de 48 horas $\left(\mathrm{CL}_{50-} 48 \mathrm{~h}\right)$, de acordo com os preceitos da norma ABNT NBR 15088 (2016). Para a realização dos bioensaios, submeteu-se o Projeto de Pesquisa ao Comitê de Ética no Uso de Animal do IFES, sendo aprovado pelo processo 23184.002809/2019-16.

Os bioensaios ecotoxicológicos foram conduzidos no laboratório de biologia do Instituto Federal do
Espírito Santo - Campus Ibatiba, baseado na norma ABNT NBR 15088 (2016) que dispões acerca da ecotoxicologia aquática, toxicidade aguda e métodos de ensaios com peixes Cyprinidae. Foram utilizados ao todo 120 organismos, adquiridos no comércio local da cidade de Ibatiba, no Espírito Santo, apresentando as seguintes características: organismos adultos de ambos os sexos, saudáveis, com o tamanho médio de $3,5 \mathrm{~cm}$ e peso em torno de $0,3 \mathrm{~g}$ a $0,5 \mathrm{~g}$ (Figura 3).

Tabela 1 - Equipamentos e métodos utilizados para cada parâmetro determinado na caracterização físico-química da Água Residuária do Café (ARC).

\begin{tabular}{|c|c|c|}
\hline Parâmetro & Unidade & Equipamentos e métodos \\
\hline Açucares & $\mathrm{mg} \mathrm{L}^{-1}$ & Conforme Albarici et al. (2009) \\
\hline Condutividade Elétrica (CE) & $d S m^{-1}$ & Condutivímetro de eletrodo - ASTM (1995) \\
\hline Cor & PCU & Espectrofotrômetro (APHA; AWWA; WEF, 2012) \\
\hline Demanda Química de & $\mathrm{mg} \mathrm{L}^{-1}$ & Espectrômetro UV - Vis - Tubos de digestão \\
\hline Oxigênio (DQO) & & APHA (2012) \\
\hline Compostos Fenólicos (CF) & $\mathrm{mg} \mathrm{L}^{-1}$ & Método de Folin Ciocauteau \\
\hline Potássio (K) & $\mathrm{mg} \mathrm{L}^{-1}$ & Espectrômeto de absorbância em chama NBR \\
\hline & & 13810 (ABNT, 1997) \\
\hline Nitrogênio Total (NT) & $\mathrm{mg} \mathrm{L}^{-1}$ & Standard Methodos (APHA, 2012) \\
\hline Oxigênio Dissolvido (OD) & $\mathrm{mg} \mathrm{L}^{-1}$ & $\begin{array}{l}\text { Oxímetro - Medidor de oxigênio dissolvido } \\
\text { datalogger (ITT 71440) }\end{array}$ \\
\hline $\mathrm{pH}$ & - & pHmetro - APHA (2012) \\
\hline Fósforo Total (PT) & $\mathrm{mg} \mathrm{L}^{-1}$ & NBR 13810 (ABNT, 1997) \\
\hline Sólidos Totais (ST) & $\mathrm{mg} \mathrm{L}^{-1}$ & Método gravimétrico \\
\hline Turbidez & NTU & Turbidímetro - (APHA; AWWA; WEF, 2012) \\
\hline
\end{tabular}

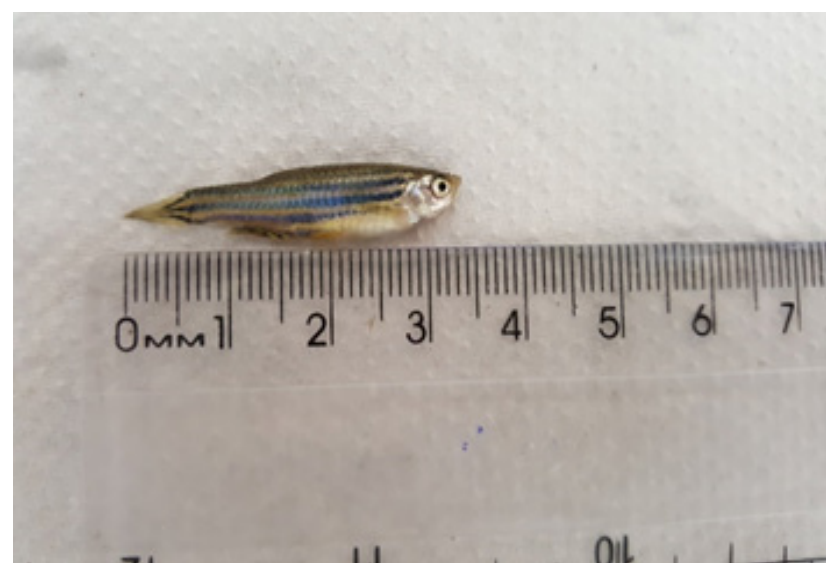

Figura 3 - Espécime adulto de peixe paulistinha (Danio rerio) com cerca 3,5 centímetros (Fonte: Autor, 2017).

Antes da realização dos bioensaios, os indivíduos foram submetidos a um curto período de aclimatação, adicionando água à temperatura ambiente aos sacos plásticos onde permaneciam por um período de 20 minutos até estabilizar a temperatura. Após este período de transição, os indivíduos foram igualmente distribuídos em dois grupos, organizados em baldes de 15 litros com água tratada e agente desclorificante, evitando, assim, efeito do cloro sobre os peixes.

Para evitar o estresse, os peixes permaneceram em ambiente calmo, sala climatizada, com o mínimo de contato com pessoas e alimentação realizada três vezes ao dia. O fotoperíodo foi de 12 horas de luz e 12 horas de 
obscuridade com a temperatura oscilando entre $24^{\circ} \mathrm{C}$ e $28^{\circ} \mathrm{C}$. Além disso, a limpeza dos aquários era realizada a cada três dias, retirando-se imediatamente os organismos mortos e renovando completamente toda a água dos aquários.

Para os ensaios ecotoxicológicos adotou-se o sistema estático e sem aeração, onde os organismos-teste foram expostos a várias concentrações da amostra por um período de 48 horas, sem alimentação e sem renovação da solução-teste, sendo avaliada ao fim dos ensaios a sobrevivência dos organismos (ABNT, 2016). A fim de estabelecer a concentração da amostra que seria utilizada no ensaio definitivo, realizou-se um ensaio preliminar com as seguintes concentrações da solução-teste: $16,7 \%, 8,33 \%$ e $4,16 \%$ de ARC equivalentes a 500,250 e $125 \mathrm{ml}$ de ARC, completados com água até atingir o volume previamente determinado de 2 litros, mantendo um grupo controle em água desclorada, considerando 4 organismos-teste por aquário (Figura 4).

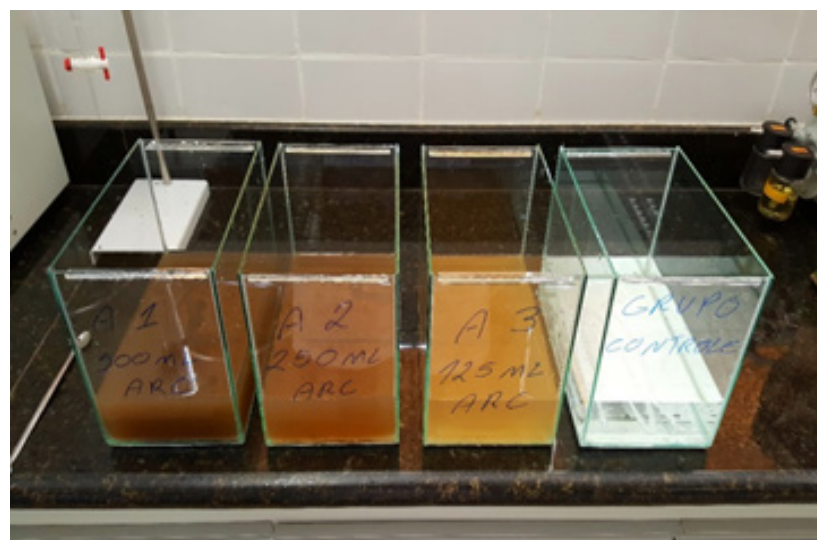

Figura 4 - Ensaio preliminar com altas concentrações da amostra equivalentes a 16,7\% (500 ml), 8,33\% (250 ml) e 4,16\% (125 ml) de ARC acompanhado de um grupo controle (Fonte: Autor, 2017).

Antes de cada ensaio os espécimes de Danio rerio foram submetidos a um período de aclimatação de 24 horas. Para o ensaio definitivo realizaram-se 5 repetições que ocorreram entre os meses de setembro a novembro de 2017 , utilizando-se 4 aquários de vidro com as dimensões $25 \times 15 \times 20$ $\mathrm{cm}$ contendo 5 organismos-teste em cada, sendo um deles o grupo controle, o qual era mantido em 3 litros de água com tratamento desclorificante. Os demais aquários de tratamento continham as seguintes concentrações da solução-teste: $1,67 \%, 3,33 \%$ e $5 \%$ de ARC correspondentes a 50, 100 e $150 \mathrm{ml}$ de ARC, posteriormente foram completados com água da torneira até alcançar o volume determinado de 3000 $\mathrm{ml}$ (Figura 5). A quantidade de água utilizada em cada aquário satisfazia a relação massa/volume de 1 grama de organismo por litro.

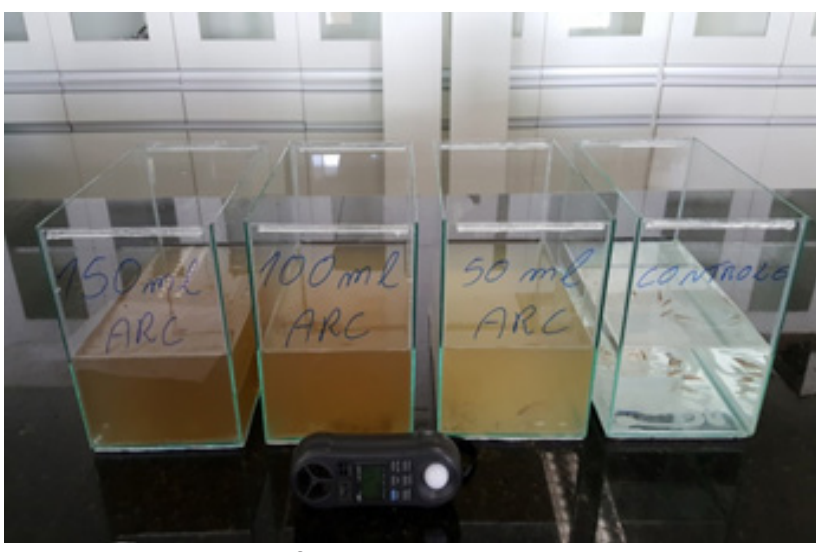

Figura 5 - Ensaio definitivo com concentrações da amostra equivalentes a 1,67\% (50 ml), 3,33\% (100 ml) e $5 \%(150 \mathrm{ml})$ de ARC acompanhado de um grupo controle (Fonte: Autor, 2017).

\section{RESULTADOS E DISCUSSÃO}

Os resultados da caracterização física e química do efluente seguem apresentados na Tabela 2. Pelos resultados expostos nas variáveis, observava-se o quanto o efluente possui potencial tóxico, demonstrando valores bem acima dos limites estabelecidos pela legislação para lançamento em curso d'água sem tratamento (Brasil, 2011), destacando-se a importância do presente estudo.

Tabela 2 - Teores médios e os desvios para cada parâmetro determinado na caracterização físico-química da Água Residuária do Café (ARC) utilizada nos bioensaios de toxicidade.

\begin{tabular}{ccc}
\hline Parâmetro & Unidade & Valores médios \\
\hline Açúcares & $\mathrm{mg} \mathrm{L}^{-1}$ & $6.950 \pm 36,5$ \\
Cor & $\mathrm{dS} \mathrm{m}^{-1}$ & $1,43 \pm 0,45$ \\
Condutividade Elétrica (CE) & $\mathrm{PCU}$ & $3.610 \pm 193$ \\
Demanda Química de Oxigênio (DQO) & $\mathrm{mg} \mathrm{L}^{-1}$ & $26.800 \pm 8.725$ \\
Compostos Fenólicos (CF) & $\mathrm{mg} \mathrm{L}^{-1}$ & $212,0 \pm 8,1$ \\
Potássio (K) & $\mathrm{mg} \mathrm{L}^{-1}$ & $471,4 \pm 55$ \\
Nitrogênio Total (NT) & $\mathrm{mg} \mathrm{L}^{-1}$ & $12,2 \pm 0,8$ \\
Oxigênio Dissolvido (OD) & $\mathrm{mg} \mathrm{L}^{-1}$ & $5,1 \pm 0,3$ \\
pH & - & $4,7 \pm 0,4$ \\
Fósforo Total (PT) & $\mathrm{mg} \mathrm{L}^{-1}$ & $16 \pm 1,2$ \\
Sólidos Totais (ST) & $\mathrm{mg} \mathrm{L}^{-1}$ & $15.818 \pm 7.184$ \\
Turbidez & $\mathrm{NTU}$ & $1.008 \pm 141$ \\
\hline
\end{tabular}

Comparando os resultados dos parâmetros analisados (Tabela 2) com outros efluentes, com características potencialmente poluidoras, como o de suinocultura estudado por Soares et al. (2010), os valores médios de DQO $\left(26.800 \mathrm{mg} \mathrm{L}^{-1}\right)$ e sólidos totais (15.818 $\mathrm{mg} \mathrm{L}^{-1}$ ) encontrados nas amostras de ARC são superiores aos valores de DQO (23.874 $\left.\mathrm{mg} \mathrm{L}^{-1}\right)$ e sólidos totais ( $13.651 \mathrm{mg} \mathrm{L}^{-1}$ ) encontrados normalmente em criadouros de suínos. Destaca-se que o elevado valor de DQO ultrapassa o permitido pela Resolução CONAMA n430 de 13/05/2011 (Brasil, 2011). Logo, se fossem despejadas nos mananciais poderiam causar graves problemas de 
poluição provocando desequilíbrios na vida aquática, mortandade de peixes e eutrofização (Campos, 2010).

O valor médio encontrado para turbidez foi de 1.008 NTU (Tabela 2) e se aproxima do valor observado por Holanda (2018) quando caracterizou a água de lavagem do biodiesel da soja, registrando valores médios de turbidez equivalentes a (1.073 NTU). A semelhança entre dois valores pode ser explicada devido ao fato de haver muitas partículas em suspensão em ambos os efluentes, oriunda da matéria orgânica em decomposição, onde tais partículas dificultam a penetração da luz e prejudica a fotossíntese, interferindo na cadeia alimentar e no equilíbrio natural do ecossistema aquático.

Aespécie Danio rerio apresenta comportamentos complexos quando comparada a roedores e humanos, podendo ser empregados e avaliados em diferentes estudos (Nabinger, 2017). Durante os ensaios para estimar a $\mathrm{CL}_{50-} 48 \mathrm{~h}$, logo nas primeiras horas de exposição às amostras das soluções-teste, foram observadas mudanças significativas no comportamento dos animais. Tais mudanças ocorrem, principalmente, pela baixa concentração de oxigênio dissolvido nas amostras de ARC na qual os animais foram expostos, Silva et al. (2015) explica que a redução de oxigênio dissolvido ocorre devido ao elevado consumo de matéria orgânica por microorganismos existentes neste efluente.

Magalhães (2007) estudando os efeitos de substâncias tóxicas no comportamento de peixes da espécie Danio rerio, comprovou que o aumento da atividade natatória esta associada ao comportamento de fuga do animal e Barton (2002) afirmou que a toxicidade da água afeta o comportamento dos peixes e gera distúrbio físicos. Em comparação com estes estudos, durante os bioensaios, foi observado com maior frequência o aumento da atividade natatória dos organismos em exposição, além de subidas repentinas à superfície, perda de equilíbrio e nado horizontal. Como a demanda por oxigênio é crescente o peixe tende a filtrar maior quantidade de água, desta forma aumenta a absorção de substâncias tóxicas e consequentemente havendo a possibilidade constante de contaminação do organismo.

No ensaio definitivo, os resultados variaram de acordo com a concentração da solução-teste. Houve relação direta crescente entre a concentração da ARC e a mortalidade, foram quantificados 21,15 , e 5 organismos mortos para as concentrações de $5 \%$, $3,33 \%$ e 1,67\% respectivamente (Figura 6 ).

Baseando-se na norma utilizada ABNT NBR 15088 (2016), os resultados alcançados podem ser considerados válidos, pois o percentual de organismos mortos no controle foi inferior a $10 \%$. Os testes apontam que a maior concentração $(5 \%)$ causou mortalidade em $84 \%$ dos organismos, na concentração $(3,33 \%)$ a mortalidade foi de $60 \%$ e na menor concentração da $(1,67 \%)$ foram registrados $20 \%$ de mortalidade (Figura 7 ).

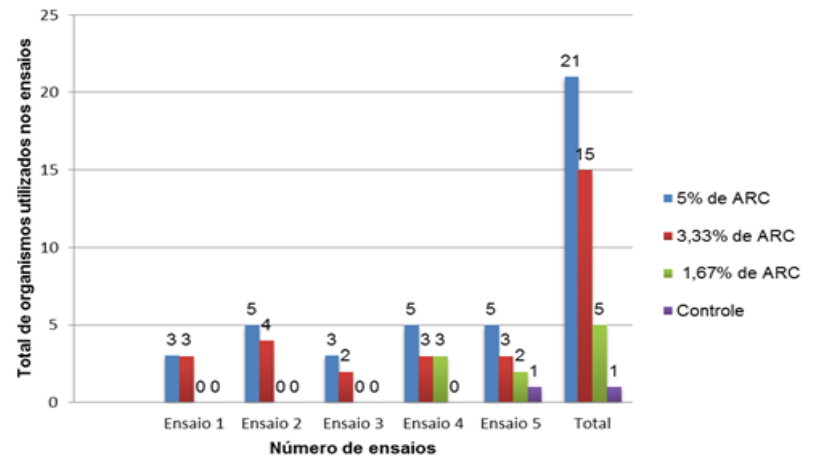

Figura 6 - Quantificação dos organismos mortos para cada ensaio (Fonte: Autor, 2018)

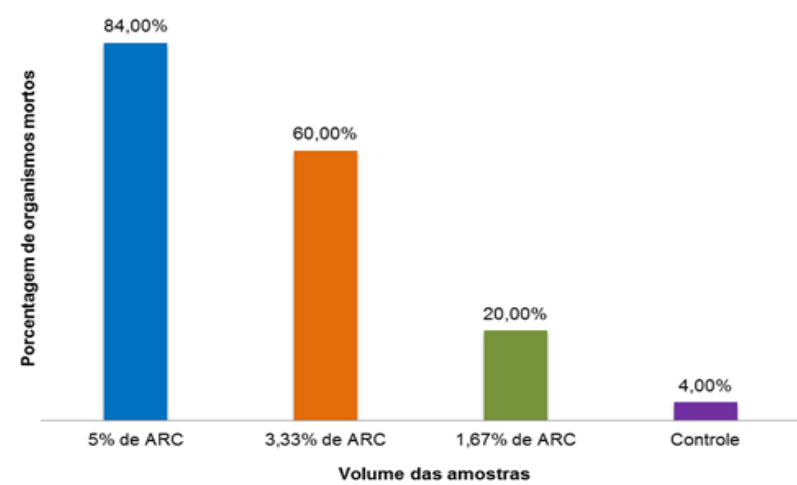

Figura 7 - Somatório do percentual de organismos mortos no ensaio definitivo após todas as repetições.

Resultados similares foram registrados por Nabinger (2017) quando expôs peixes da espécie Danio rerio ao elemento químico níquel, um metal pesado extremamente tóxico para organismos aquáticos. Nabinger (2007) observou que o maior índice de mortalidade dos organismos está relacionado ao aumento da concentração de níquel nas amostras. O mesmo efeito foi observado neste estudo, o percentual de organismos mortos tende a aumentar de acordo com o aumento da concentração do efluente.

Os bioensaios ecotoxicológicos revelam que todas as amostras de ARC apresentaram efeito tóxico na espécie Danio rerio. Os resultados observados nos bioensaios indicam ainda, que $\mathrm{CL}_{50_{-}} 48 \mathrm{~h}$ se encontra entre as concentrações $5,0 \%$ e $3,33 \%$ de diluição da ARC, demonstrando que a taxa de mortalidade oscilou entre $20 \%$ e $60 \%$ dessa concentração.

A alta taxa de mortalidade dos organismos nas baixas concentrações estudadas da ARC expõe o potencial poluidor da ARC, oriunda, possivelmente aos compostos fenólicos existentes. Zanin et al. (2014) citam, que grande parte da contaminação química de 
ambientes aquáticos pode ser atribuída aos compostos fenólicos oriundos de águas residuárias. Cita-se ainda, que além de apresentar alta toxicidade, estes compostos são rapidamente absorvidos pelo organismo humano se acumulando em órgãos como o fígado e o pulmão (Bonini et al., 2015).

Os compostos fenólicos destacam como os principais agentes tóxicos, pois esses apresentam-se bem acima dos limites permitidos para o lançamento nos mananciais, descrito pela resolução CONAMA $N^{\circ} 430$ de 2005 (Brasil, 2011). Tais substâncias oferecem riscos à saúde dos seres vivos, podem inibir os processos biológicos, estimular células cancerígenas e atuar como desreguladores endócrinos nos organismos (Bruno \& Oliveira, 2008). Os compostos fenólicos, encontrados no solo e na água, dificilmente são degradados ou reciclados na natureza, dessa forma podem permanecer por longos períodos no ambiente, causando danos ambientais preocupantes.

\section{CONSIDERAÇÕES FINAIS}

As análises dos parâmetros físicos e químicos das ARC indicaram valores acima do limite estabelecido pela Resolução CONAMA n430 de 13/05/2011. Portanto, mesmo que este efluente sofra diluição quando lançado nos mananciais, ainda se faz necessário avaliar sua toxicidade para outras espécies de ocorrência natural nos ecossistemas aquáticos, as quais podem vir a sofrer diferentes alterações em decorrência do período de exposição.

Os bioensaios apontaram que o espécime Danio rerio se mostrou bastante afetado pelas concentrações deARC demonstrando comportamento atípico, explicado pelo fato desta espécie apresentar grande sensibilidade a compostos químicos que alteraram de alguma forma seu ambiente natural ocasionando mudanças severas e muitas vezes irreparáveis.

A ação poluente dos compostos fenólicos, associadaà redução do oxigênio dissolvido nas amostras, provocou a mortandade os indivíduos estudados. Tais alterações comprovam que a toxicidade da ARC é extremamente prejudicial para a vida aquática, representando riscos principalmente para as espécies de peixes.

$\mathrm{A} \mathrm{CL}_{50-} 48 \mathrm{~h}$ da ARC encontra-se acima da concentração de $3,33 \%$ de diluição da ARC à água limpa. Assim, uma unidade de beneficiamento dos grãos (despolpador) poderá poluir um curso d'água

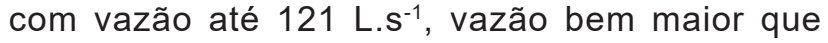
muitos rios da região que recebem esse tipo de efluente não tratado.

\section{REFERÊNCIAS}

ALVARO, T. T.; CESAR, R. G.; POLIVANOV, H.; EGLER, S. G. Avaliação ecotoxicológica de solos tropicais tratados com lodo de esgoto utilizando bioensaios com organismos aquáticos. Jornada de iniciação científica, Rio de Janeiro: CETEM/ MCTI, 2010.

APHA, 2012. Standard Methods For The Examination Of Water And Wastewater, 22nd Ed.: American Public Health Association, American Water Works Association, Water Environment Federation. Washington, DC.

ASSOCIAÇÃO BRASILEIRA DE NORMAS TÉCNICAS. NBR 15088: Ecotoxicidade aquática Toxicidade aguda - Método de ensaios com peixes (Cyprinidae). 3 ed. Rio de Janeiro, 2016. 25 p.

BARTON, B. A.. Stress in Fishes: A Diversity of Responses with Particular Reference to Changes in Circulating Corticosteroids. Integrative And Comparative Biology, [s.I.], v. 42, n. 3, p.517525, 1 jul. 2002. Oxford University Press (OUP). http://dx.doi.org/10.1093/icb/42.3.517.

BONINI, J. S.; MARIANE, F. Q.; CASTRO, E. G.; MARANGONI, R. ANAISSI, F. J. Partículas de CoO $(\mathrm{OH})$ dispersas em pasta de carbono aplicado na eletrooxidação de compostos fenólicos. Orbital: The Electronic Journal of Chemistry, v. 7, n. 4, p. 318-326, 2015.

BRANDOLT, T. D.; LOBO, E. A. Avaliação ecotoxicológica utilizando bioensaios com Daphina magna em água de lavoura de arroz no município de mostardas, rs, brasil. Tecno-Lógica, v. 14, n. 2, p. 47-51, 2010.

BRUNO, M.; OLIVEIRA, R. A. Tratamento anaeróbio de águas residuárias do beneficiamento de café por via úmida em reatores UASB em dois estágios. Engenharia Agrícola, p. 364-377, 2008.

BUENO,A.P. M.; VASCONCELOS, M. G.; FRANCISCO, C. M.; PAVANIN, L. A. Teste de micronúcleos em peixes e parâmetros físico-químicos da água da represa Cocais, Minas Gerais. Acta Brasiliensis, v. 1, n. 3, p. 32-36, 2017.

CAMPOS, C. M. M.; PRADO, M. A. C.; PEREIRA, E. L. Caracterização físico-química, bioquímica e energética da água residuária do café processado por via úmida. Bioscience Journal, v. 26, n. 4, 2010.

CONAMA. Resolução $n^{\circ} 430$ de 13 de maio de 2011. Dispõe sobre as condições e padrões de lançamento de efluentes, complementa e altera a resolução $\mathrm{n}^{\circ} 357$ de 17 de março de 2005 do Conselho Nacional do Meio Ambiente-CONAMA. Ministério do Meio Ambiente, Brasília, DF, 13 de maio de 2011. Disponível em: <http://www.mma. 
gov.br/port/conama/legiabre.cfm?codlegi=646>. Acesso em 21 de junho de 2018.

COSTA, D. G.; DE CAMPOS, T. M. P.; CESAR, R. G.; CASTILHOS, Z. C.; DA ROCHA, B. C. R. C. Ecotoxicidade do 2, 4-D a oligoquetas em função do tipo de solo. Revista Brasileira de Herbicidas, v. 14, n. 3, p. 248-255, 2015.

SILVA, B. M.; RAVANELI, M. A. C.; PASCHOALATO, C. F. P. R. Toxicidade aguda dos herbicidas diuron e hexazinona à Danio rerio. Pesticidas: Revista de Ecotoxicologia e Meio Ambiente, v. 20, 2010.

OLIVEIRA, T. N. D. ; DE CARVALHO, J. P. V.; FREIRAS, A. C. S.; TEIXEIRA, J. S. Água residuária de lavagem e despolpa de café na fazenda toca da onça em encruzilhada-bahia: avaliação de aspectos e impactos ambientais. Enciclopédia Biosfera, Goiânia, v. 6, n. 9, p.3-4, 2010.

FURLEY, T. H.; DE MELLO, F. A.; SIQUEIRA, J. B. L. Principais questões ambientais causadas pelos efluentes de fábricas de celulose da América latina. O papel, v. 79, n. 4, p. 70-77, 2018.

HIGASHI, E. S. Bioensaios de toxicidade da água do efluente de biofiltros em areia como ferramenta de avaliação da qualidade da água. 2016. Tese de Mestrado em Ciências: Engenharia Hidráulica e Saneamento. Universidade de São Paulo.

HOLANDA, J. N.; MACIEL, A. P.; SANTOS, R. L. Avaliação ecotoxicológica da água de lavagem da purificação de biodiesel de soja metílico utilizando Danio rerio como organismo-teste. Boletim do Laboratório de hidrobiologia, v. 25, n. 1, 2018.

MAGALHÃES, D. P.. Avaliação de um sistema de análise de imagem em tempo real para monitoramento de efeito tóxico no comportamento natatório do peixe Danio rerio (Hamilton, 1822). 2007. Dissertação de Mestrado em Ciências na Área de Saúde Publica. Escola Nacional de Saúde Publica Sérgio Arouca.

MELLO, R. M. Estudo de alterações no metabolismo de carboidratos do zebrafish (danio RERIO) em águas contendo cromo hexavalente. 2017. Dissertação de Mestrado em Avaliação de Impactos Ambientais. Centro Universitário La Salle - UNILASALLE.

NABINGER, D. D. Exposição aguda e subcrônica ao níquel em peixe-zebra (Danio rerio): avaliação de parâmetros morfológicos e comportamentais. 2017. Dissertação de Mestrado em Biologia Celular e Molecular. Pontifícia Universidade Católica do Rio Grande do Sul. Faculdade de Biociências.

OTTONELLI, C. K. R. Avaliação ecotoxicológica de efluente hospitalar utilizando ensaios embrionários com Danio Rerio. 2017. Dissertação de Mestrado em Ciências e Tecnologia Ambiental. Universidade Federal da Fronteira do Sul - UFFS.

PIN, B. V. R.. Aproveitamento energético do biogás da digestão anaeróbia da água residuária do café no Sul de Minas Gerais. 2018. Dissertação de Mestrado em Engenharia de Energia. Universidade Federal de Itajubá.

PREZOTTI, L. C.; MORELI A. P.; SOARES, A. F.; DA $\mathrm{ROCHA}, \mathrm{A}$. C. Teores de nutrientes nas águas residuárias do café e características químicas do solo após sua aplicação. Vitória, ES: Incaper, 2012.

SILVA, G. B.; ROLIM, M. M.; PEDROSA, E. M. R.; BEBÉ, F. V.; SILVA, E. F. F. Efeito da aplicação de água residuária da lavagem dos frutos de café sobre as propriedades químicas do solo. Engenharia Agrícola, v. 31, n. 1, p. 158-166, 2011.

SILVA, L. C. da; MORELI, A. P.; JOAQUIM, T. N. M. Café: beneficiamento e industrialização. In: MARCOLAN, A. L.; ESPINDULA, M. C. (Ed.). Café na Amazônia. Brasília, DF: Embrapa, 2015. p. 383 - 389. Capítulo 17.

SILVA, S. R. Quantificação de substâncias com atividade estrogênica e caracterização da toxicidade embriolarval em zebrafish (Danio rerio) nos efluentes das estações de tratamento de esgotos sul e norte e no Lago Paranoá, BrasíliaDF. 2015. Dissertação de Mestrado em Biologia Animal. Universidade de Brasília. Instituto de Ciências Biológicas.

SOARES, M. T. S.; GALVANIL, F.; FERNANDES, A. H. B. M.; FERNANDES, F. A.; OLIVIERI, F. L.; DE LIMA, I. B. T.; CRISPIM, S. M. A.; FRANDO, E.; RIEGER, K. L. Caracterização físico-química de efluentes líquidos de granjas suínas tratados em biodigestor. In: Embrapa Pantanal-Artigo em anais de congresso (ALICE). Simpósio sobre recursos naturais e socioeconômicos do pantanal, 5., 2010, Corumbá, MS. Anais... Corumbá: Embrapa Pantanal: UFMS; Campinas: ICS do Brasil, 2010. 1 CD-ROM SIMPAN 2010., 2010.

THOMÉ, R. G.; DA SILVA, P. M.; DOS SANTOS, H. B. Avaliação de Genotoxidade da Água de um Rio Urbano Utilizando Estudo de Células Sanguíneas de Danio rerio. Conexão Ciência (Online), v. 11, n. 2, p. 9-16, 2016.

ZANIN, E.; DA SILVA, I. E. C.; LOPES, T. J.; CANCELIER, A.; COSTELI, M. C.; DA SILVA, A. Estudo da degradação de compostos fenólicos presente em águas residuárias de postos de combustíveis utilizando fungos filamentosos (Aspergillus flavus). Revista Eletrônica em Gestão, Educação e Tecnologia Ambiental, [s.I.], v. 18, n. 1, p.279-287, 7 abr. 2014. Universidade Federal de Santa Maria. 
SOUZA, E. D. V. et al., (2020). Avaliação Ecotoxicológica com Danio rerio. 